\section{Hemothorax resulting from venous tearing by a catheter}

Taiga Itagaki, Hiromi Katoh, Yushi U. Adachi, Katsumi Suzuki, Yukako Obata, Matsuyuki Doi, and Shigehito Sato

Intensive Care Unit of University Hospital, Hamamatsu University School of Medicine, 1-20-1 Handayama, Higashi-ku, Hamamatsu City 431-3192, Japan

To the editor: We read the article by Innami et al. [1] with great interest. Hemothorax is one of the most serious adverse sequelae of internal jugular vein catheterization [2]. We encountered the same iatrogenic complication in a 10-year-old girl [3] using CV Regafohsu SX catheter (Terumo, Tokyo, Japan) equipped with an angle-tip guidewire. Innami et al. [1] concluded that the angle-tip guidewire had directly punctured the right brachiocephalic vein in their patient. Although this mechanism could explain the incident comprehensively, our experimental evaluation [3] demonstrated that extraluminal penetration by a soft, limp guidewire itself would be very rare and would occur only in exceptional cases. In our previous experience, and in an in vitro study, the vessel wall was finally torn by the catheter, not by the wire, and a small hole was observed macroscopically after the removal of the catheter [3, 4]. We speculate that a soft, thin, angle-tip guidewire could not cause perforation of a vessel wall, but that such a guidewire, unlike a J-tip guidewire, might incidentally migrate into a small branch directly divided from the large brachiocephalic vein. Once a thin straight guidewire is deeply inserted into the distal branch of a vessel, the rebound of the guidewire into a large vessel might be restrained during catheterization, and malpositioning of the guidewire would be followed by venous tearing with a large-bore dilator or a catheter. We have no clinical evidence concerning the relationship between the shape of a guidewire and the safety of vein catheterization [5]. The size of the puncturing needle used with an angle-tip guidewire is usually smaller than that of the puncturing needles used with J-tip guidewires. However, like Innami et al. [1], we also recommend not to use an angle-tip guidewire, from the view point of the possible migration of such guidewires.

\section{References}

1. Innami Y, Oyaizu T, Ouchi T, Umemura N, Koitabashi T. Lifethreatening hemothorax resulting from right brachiocephalic vein perforation during right internal jugular vein catheterization. J Anesth. 2009;23:135-8.

2. Jankovic Z, Boon A, Prasad R. Fatal haemothorax following largebore percutaneous cannulation before liver transplantation. Br J Anaesth. 205;95:472-6.

3. Itagaki T, Adachi Y, Suzuki K, Obata Y, Doi M, Sato S. Hemothorax resulting from venous tearing by the catheter during the internal jugular approach. J Clin Anesth (Jpn). 2008;32:1423-5.

4. Reina MA, de Leon-Casasola O, Lopez A, De Andres J, Martin $\mathrm{S}$, Mora M. An in vitro study of dural lesions produced by 25 -gauge Quincke and Whitacre needles evaluated by scanning electron microscopy. Reg Anesth Pain Med. 2000;26:393-402.

5. Domino KB, Bowdle TA, Posner KL, Spitellie PH, Lee LA, Cheney FW. Injuries and liability related to central vascular catheters. A closed claims analysis. Anesthesiology. 2004;100:1411-8.

Address correspondence to: Y.U. Adachi

Received: April 27, 2009 / Accepted: June 18, 2009 